\title{
Study of Optical MIMO Transmission Systems Using the MGDM Multiplexing Technique
}

\author{
N. Elhajrat ${ }^{1}$, O. Elouatssi ${ }^{1}$, A. El Abbassi ${ }^{2}$, F. Essahlaoui ${ }^{2} \&$ M. Aftatah ${ }^{3}$ \\ ${ }^{1}$ Team of Optoelectronics and Applied Energy Technologies, Dept. of Physics, FST, B.P. 509, Boutalamine, \\ Errachidia, My Ismail University of Meknes, Morocco \\ 2 Team of Electronics, Physical Instrumentation and Measurements, Dept. of Physics, FST, B.P. 509, \\ Boutalamine, Errachidia, My Ismail University Meknes, Morocco. \\ ${ }^{3}$ Faculty of Sciences and Techniques, Sultan MoulaySlimane University, BeniMellal, Morocco \\ Correspondence: N. Elhajrat, Team of Optoelectronics and Applied Energy Technologies, Dept. of Physics, FST, \\ B.P. 509, Boutalamine, Errachidia, My Ismail University of Meknes, Morocco
}

Received: November 29, 2019

Accepted: December 25, 2019 Online Published: December 26, 2019

doi:10.5539/mas.v14n1p34

URL: https://doi.org/10.5539/mas.v14n1p34

\begin{abstract}
In current local area networks, multimode fibers (MMFs), mainly graded index (GI) MMFs, are the main types of fibers used for data communications. Because of their high bandwidth, they are considered the main method of transmission that allows to offer multiservice broadband services using optical multiplexing techniques.

The MGDM (ModeGroup Division Multiplexing) is a Multiplexing technique, which aims to improve the performance of the multimode optical fiber by spatially multiplexing the data streams to be transmitted. In this work, we study optical MIMO (multi-input multi-output) transmission systems on an MMF optical fiber, specifically the adaptation of the architecture of MIMO transmission systems. In this context, we have studied the mode group multiplexing technique (MDGM), to evaluate the transmission capacity. In fact, the latter depends on the injection conditions and the state of the optical fiber.
\end{abstract}

Keywords: Optical MIMO, multimode fiber O-MGDM and transmission capacity

\section{Introduction}

Multimode fiber (MMF), is a very interesting method of transmission due to its low cost compared to single mode fiber (SMF), in indoor broadband networks (Koonen, 2006).

The main objectives are the optimization of these networks for the transport of a particular set of services (voice telephony, Internet, etc.) to the end user and the integration of new broadband services. Because of its broad bandwidth, MMF is the only medium capable of offering a multi-service broadband in office and indoor networks, using multiplexing techniques. To simultaneously transport different types of services (having different bandwidths, specific signal formats, various requirements in terms of quality of service (QoS)), such multiplexing technique must respect a high efficiency/cost ratio.

As part of improving the bandwidth of optical fiber MMF, several methods have been applied to optics. These methods include Wavelength Division Multiplexing (WDM) (Gu et al., 2006), optical Frequency Division Multiplexing (O-FDM) (Nishio and Numai, 2013), the space division multiplexing (SDM) (Winzer et al., 2014)(Mizuno and Miyamoto, 2017), the optical Time division multiplexing O-TDM (Chi et al., 2014) and the mode group diversity multiplexing (MGDM) technique (Tsekrekos, 2008)(Chen et al., 2011).

In the following we will focus on the mode group diversity multiplexing (MGDM) technique, which is a developed version of a wireless transmission chain known as the BLAST (Basic Local Alignment Search Tool) (Kuchta et al., 2004).

The MGDM multiplexing technique is based on the spatial detection and launching of subgroups to create a number of independent communication channels on a single MMF fiber, which increases the transmission capacity (Baklouti and Attia, 2013).

In principle, the MGDM technique is similar to the MIMO (multiple input - multiple output) system in radio communications. 
This paper is organized as follows. In Part 1, we describe the principle of the MGDM system. In Part 2, we study the conditions of injections. In part 3, we run simulations of this system. And we end with a conclusion.

\section{System Model}

The principle of the mode group multiplexing (MGDM) technique is shown in Figure 1.

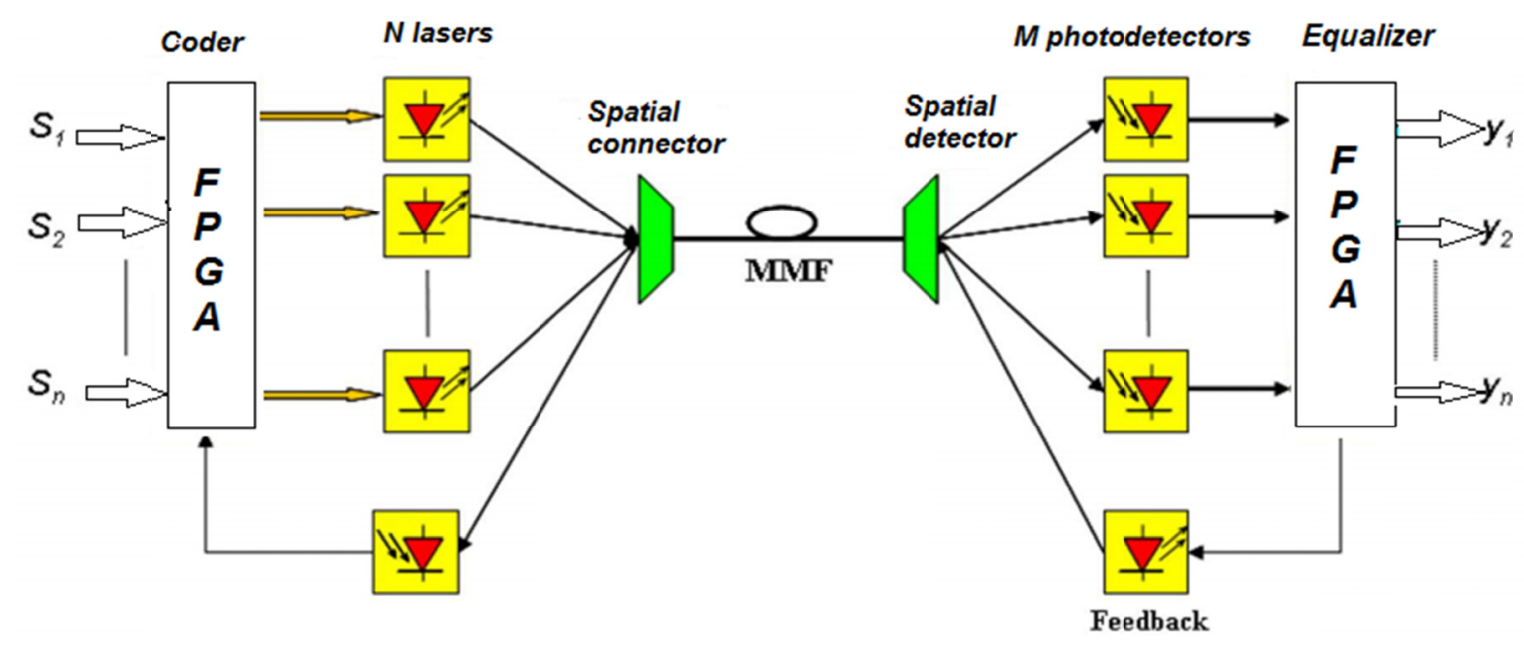

Figure 1. Block diagram of an MGDM optical transmission chain.

This system consists of $\mathrm{N}$ transmitters (Lasers), and $\mathrm{M}$ receivers (photo-detectors) such as $\mathrm{N} . \leq \mathrm{M}$. So we can write the equation of the output signal $y_{i}$ according to the input signal $s_{i}$ in the following form:

$$
\mathrm{Y}=\mathrm{H} . \mathrm{s}+\mathrm{n}
$$

With $\mathrm{H}$ and $\mathrm{n}$, respectively, the matrix of the channel and the carrier of the additive noise of the receiver.

The elements $h_{i, j}$ of the matrix describe the transfer of the signal of the transmitter $i$, to the receiver $j$, they express themselves as (Awad et al., 2011):

$$
\mathrm{h}_{\mathrm{i}, \mathrm{j}}=\frac{\mathrm{I}_{\mathrm{j}}\left(\mathrm{S}_{\mathrm{i}} \mathrm{L}\right)}{\mathrm{I}_{\mathrm{j}}(\mathrm{S}, \mathrm{L})}
$$

With $\mathrm{I}_{\mathrm{j}}$ : the intensity of the luminous flux caused by the emitter $\mathrm{j}$, measured at the exit of the fiber of length $\mathrm{L}$ and $S_{i}$ : the surface of the segment of the $i$ th detector on the facet of the output of the figure 2 .

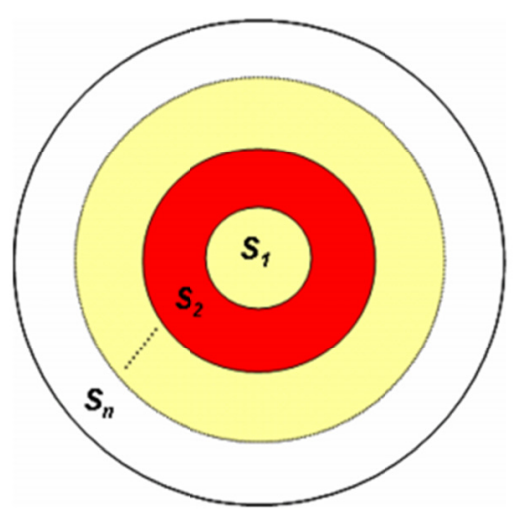

Figure 2. Facet of fiber output for $\mathrm{N}$ receivers

Considering that the matrix of the channelHis known to the receiver, the capacity of transmission is expressed as follows (Telatar, 1999): 


$$
\mathrm{C}=\operatorname{Blog}_{2}\left[\operatorname{det}\left(\mathrm{I}_{\mathrm{k}}+\frac{\mathrm{SNR}}{\mathrm{M}} \mathrm{HH}^{*}\right)\right]
$$

Where, $\left(^{*}\right)$ is the conjugate transpose, M is the number of modes of the MMF fiber and B is the bandwidth of the fiber.

\section{Excitation Condition in the MGDM System}

For an MGDM system, the incident field at the input side of the optical fiber is considered a Gaussian characterized by three parameters that determine the state of excitation of MMF, these parameters are (Raddatz et al., 1998) :

Radial offset (F)

Spot size (w)

angular offset $(\theta)$

These parameters affect the capacity and transmission quality in the fiber by MGDM. In the following we study the choice of these parameters.

\subsection{The Choice of Radial Offset (F) and Spot Size (w)}

The distribution of the intensity of the luminous flux at the output of the fiber depends on the number of modes excited at the entrance of the fiber.

So the relation between radial offset $\mathrm{F}$ and spot size $\mathrm{w}$ is expressed as follows (Calzavara et al., 1984.):

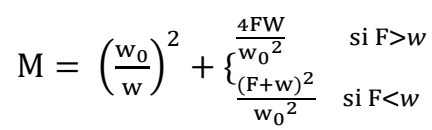

And the choice of the radial offset is related to the optimization of the injection conditions in order to minimize the interferences between the channels

\subsection{The Choice of Angular Offset}

It is possible to reduce the crosstalk between the channels by introducing the injection of the luminous flux with an angular offset compatible with the launching of helical rays. For a helical radius, there exists a unique angle $(\theta)$ as a result for each radial offset $(\mathrm{F})$, the relation between $\theta$ and $\mathrm{F}$ is given by (Calzavara et al., 1984.):

$$
\theta=\operatorname{arsin}\left(\frac{\mathrm{F} \cdot \mathrm{n}_{0} \sqrt{2 \Delta}}{\mathrm{a} . \mathrm{n}}\right)
$$

Where," a" is the diameter of the optical fiber, $n$ is the refractive index.

\section{Simulation of the Capacity of the MGDM System4.1 Transmission Capacity}

Figure 4 shows the effect of transmission and reception conditions on the change of the capacity of the system. As shown in the figure, the capacity of the $(2 \times 2)$ system is significantly reduced compared to $(3 \times 3)$ channels, (reduced by $22 \mathrm{bits} / \mathrm{s} / \mathrm{Hz}$ at $17 \mathrm{bits} / \mathrm{sec} / \mathrm{Hz}$ for $\mathrm{SNR}=30 \mathrm{~dB}$ ). The transmission conditions of the MGDM channels depend on the excitation conditions $\mathrm{F}, \mathrm{w}$ and $\theta$. 


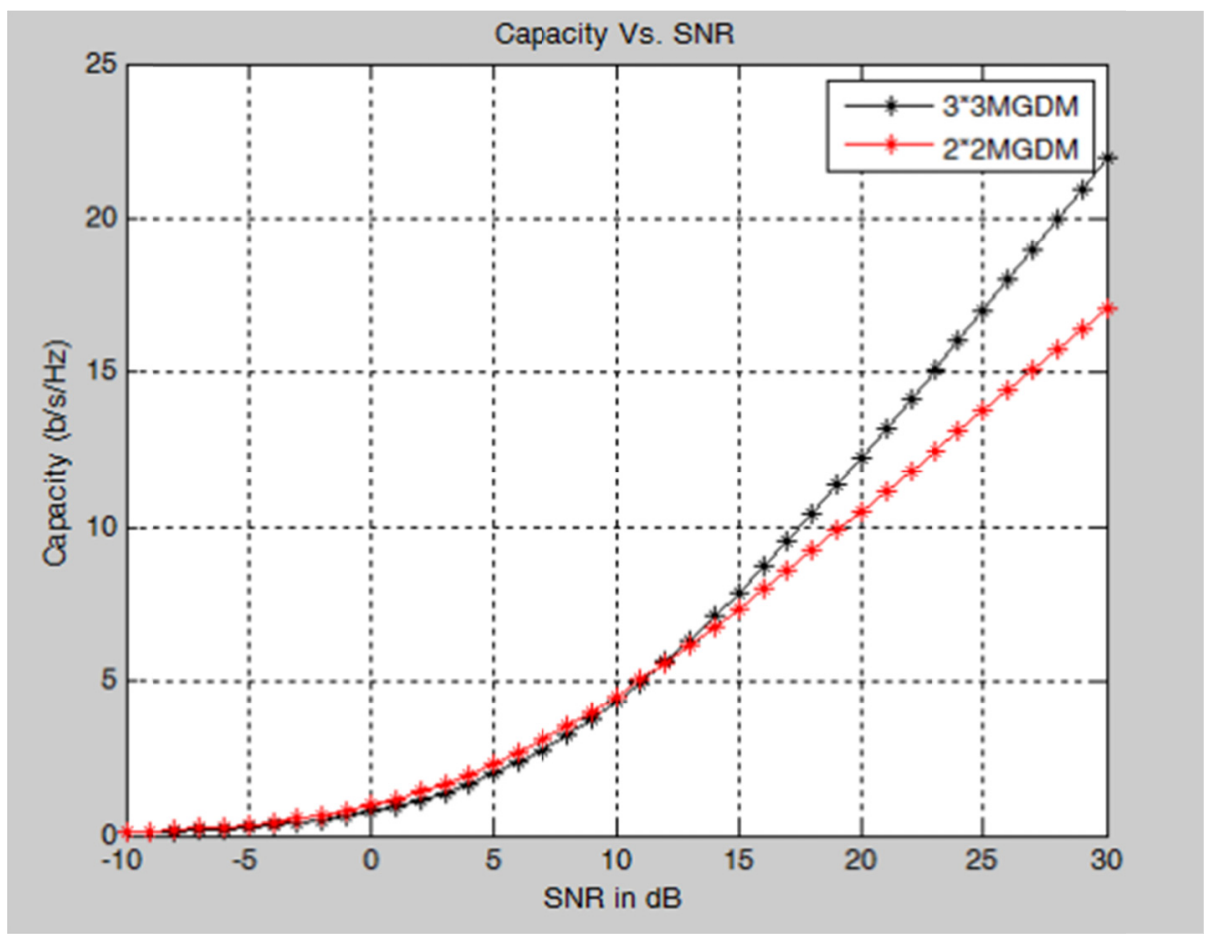

Figure 4. The capacity of the MGDM system

\subsection{Simulation with Optisystem Software}

In this part we will realize an optical transmission chain composed of a multimode optical fiber of core diameter $\mathrm{d}=62.5 \mu \mathrm{m}$ and attenuation of $0.25 \mathrm{~dB} / \mathrm{Km}$, a laser that will fix the wavelengths, a photodiode to transform the optical signals into radio signals.

Figure 4 shows a diagram of the optical transmission chain.

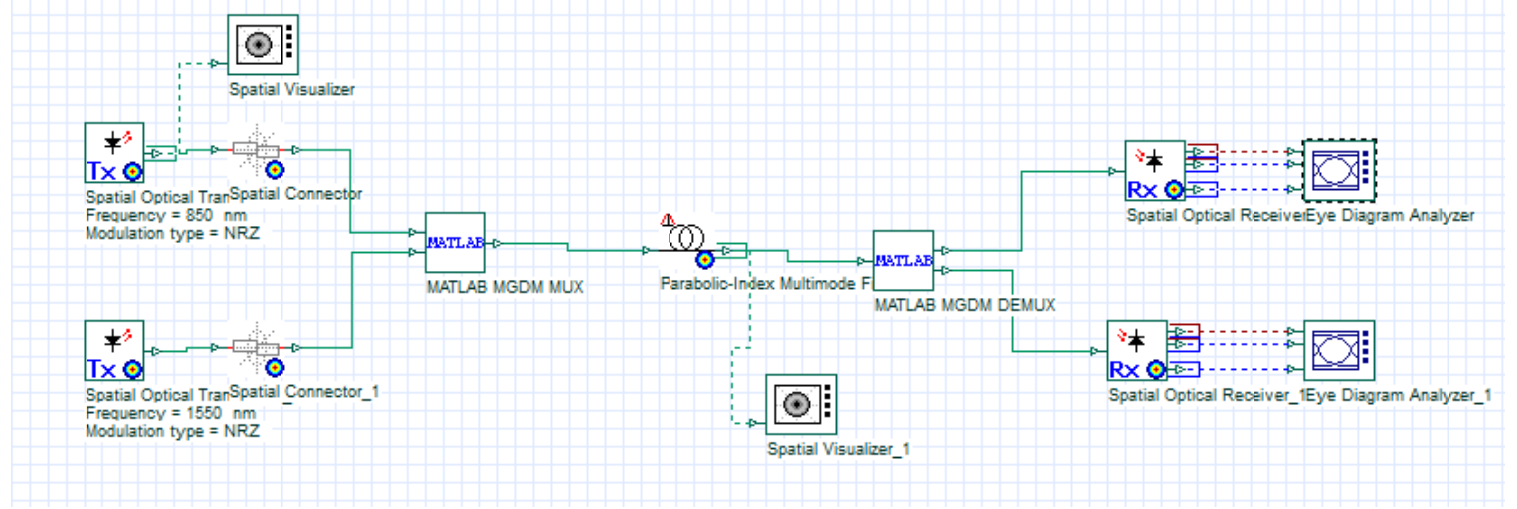

Figure 4. System transmission chain $(2 \times 2)$ MGDM

\subsection{Simulation Results}

The following results serve to study the effect of multimode optical fiber length on the performance of the $(2 \times 2)$ MGDM system.

For this we used three lengths $\mathrm{L} 1=100 \mathrm{~m}, \mathrm{~L} 2=400 \mathrm{~m}$ and $\mathrm{L} 3=4 \mathrm{Km}$.

After simulation we present in reception the shape of the obtained eye-diagram: 


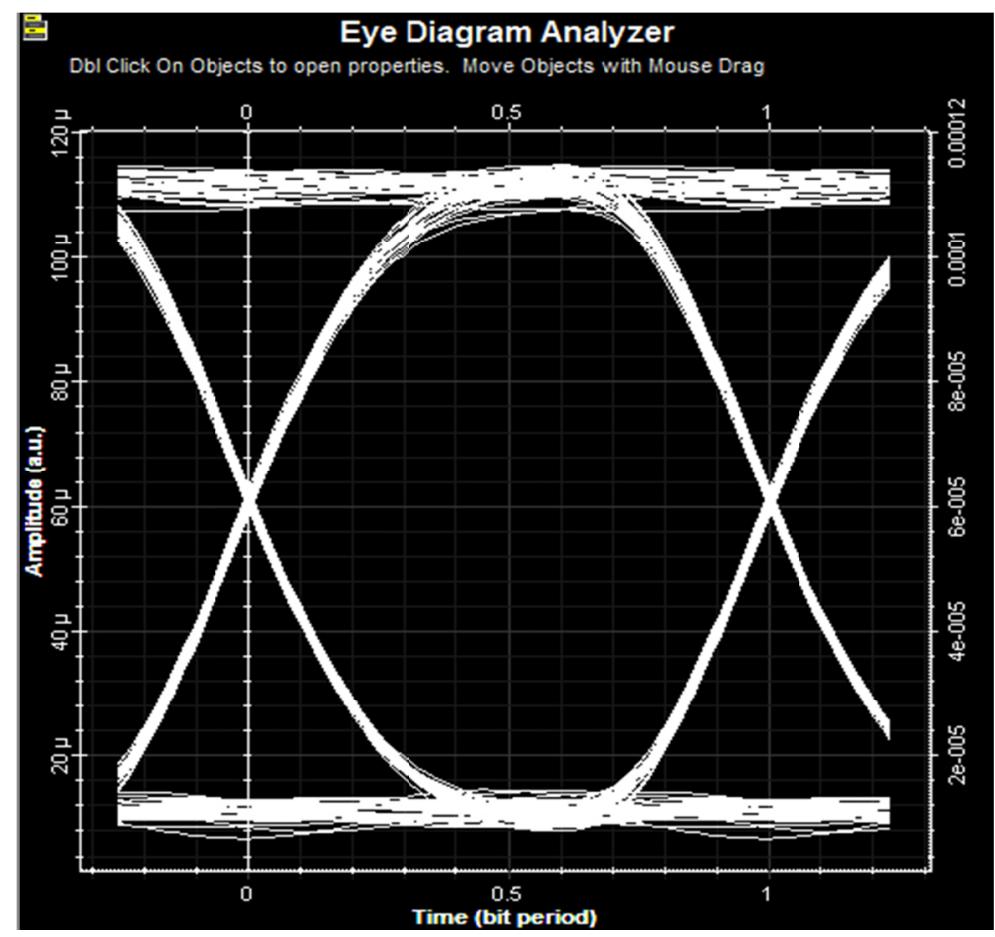

Figure 5. Eye-diagram for an optical fiber of length L1 $=100 \mathrm{~m}$

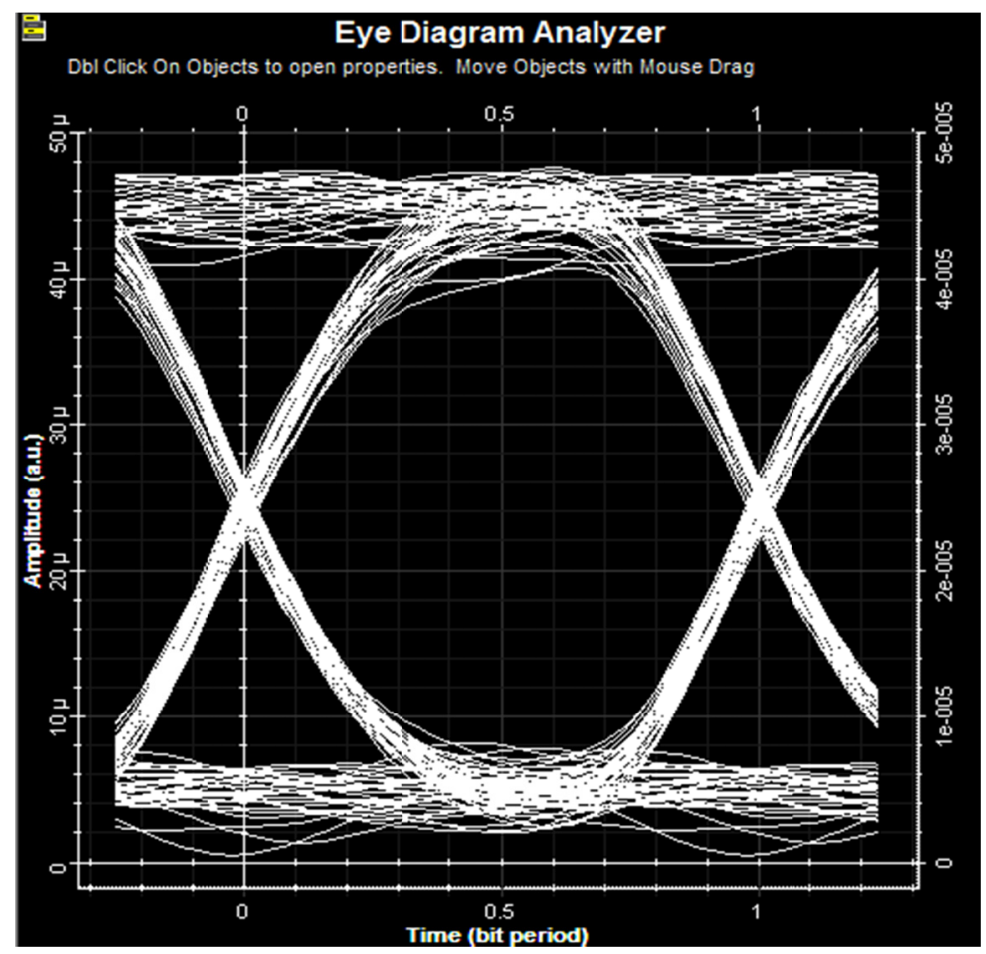

Figure 6. Eye-diagram for an optical fiber of length $L 2=400 \mathrm{~m}$. 


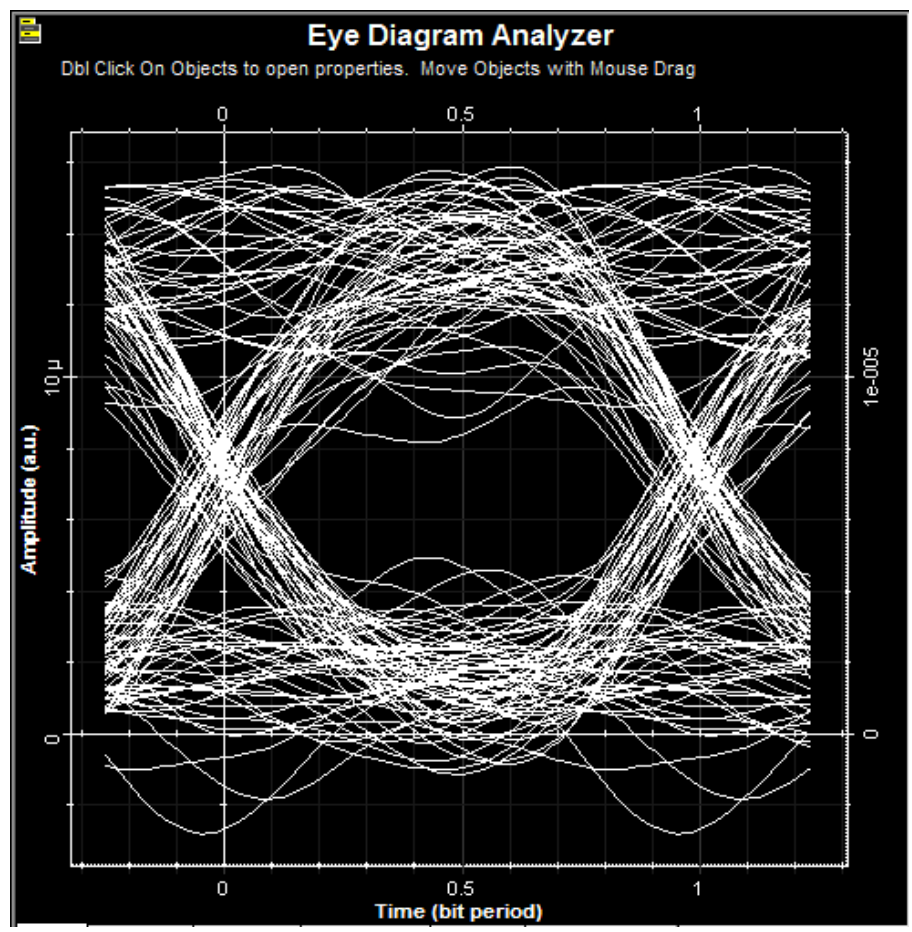

Figure 7. Eye-diagram for an optical fiber of length $\mathrm{L} 3=4 \mathrm{Km}$

\subsection{Discussion of Results}

We simulated the transmission system $(2 * 2)$ MGDM by setting the injection parameters (offset, spot size and angular offset), and by changing the length of the optical fiber.

We have drawn the eye diagram for a length $\mathrm{L}=100 \mathrm{~m}$ and we found a good opening (Figure 5), for the length $\mathrm{L} 2=400 \mathrm{~m}$, we have a fairly open eye (Figure 6 ), then for the length $\mathrm{L} 3=4 \mathrm{Km}$ we found a bad opening (Figure $7)$.

\section{Conclusion}

In this paper, we have studied and analyzed the performance of the MGDM system, by studying the optimization of the injection, detection and length parameters of the MMF fiber using the Optisystem software in order to simulate the transmission capacity of the MGDM system O-MIMO via Matlab.

In our future research, we will try to experimentally realize our $(3 \times 3)$ MGDM $(2 \times 2)$ MGDM system.

\section{References}

Awad, M., Dayoub, I., Hamouda, W., \& Rouvaen, J.-M. (2011). Adaptation of the Mode Group Diversity Multiplexing Technique for Radio Signal Transmission Over Multimode Fiber. J. Opt. Commun. Netw, 3, 1. https://doi.org/10.1364/JOCN.3.000001

Baklouti, F., \& Attia, R. (2013). Increasing the capacity of O-MIMO systems using MGDM technique by transfer matrix decomposition, in: 2013 International Conference on Electrical Engineering and Software Applications. Presented at the 2013 International Conference On Electrical Engineering and Software Applications (ICEESA), IEEE, Hammamet, Tunisia, pp. 1-6. https://doi.org/10.1109/ICEESA.2013.6578368

Calzavara, M., Caponi, R., \& Cisternino, F., n.d. Selective Excitation of Annular Zones in a Graded Index Multimode Fiber. J. Opt. Commun. 5. https://doi.org/10.1515/joc-1984-0302

Chen, H.S., van den Boom, H.P.A., \& Koonen, A.M.J. (2011). 30-Gb/s 3\$, timesl,\$3 Optical Mode Group-Division-Multiplexing System With Optimized Joint Detection. IEEE Photonics Technol. Lett, 23, 1283-1285. https://doi.org/10.1109/LPT.2011.2158639

Chi, C.-C., Lin, H.-M., Tarn, C.-W., \& Lin, H.-L. (2014). Cost-effective and monitoring-active technique for TDM-passive optical networks. Opt. Fiber Technol, 20, 434-441. https://doi.org/10.1016/j.yofte.2014.05.008 
Gu, X.J., Mohammed, W., \& Smith, P.W. (2006). Demonstration of all-fiber WDM for multimode fiber local area networks. IEEE Photonics Technol. Lett. 18, 244-246. https://doi.org/10.1109/LPT.2005.861538

Koonen, T. (2006). Fiber to the Home/Fiber to the Premises: What, Where, and When? Proc. IEEE, 94, 911-934. https://doi.org/10.1109/JPROC.2006.873435

Kuchta, D.M., Kwark, Y.H., Schuster, C., Baks, C., Haymes, C., Schaub, J., Pepeljugoski, P., Shan, L., John, R., Kucharski, D., Rogers, D., Ritter, M., Jewell, J., Graham, L.A., Schrodinger, K., Schild, A., \& Rein, H.-M. (2004). 120-Gb/s VCSEL-Based Parallel-Optical Interconnect and Custom 120-Gb/s Testing Station. J. Light. Technol, 22, 2200-2212. https://doi.org/10.1109/JLT.2004.833255

Mizuno, T., \& Miyamoto, Y. (2017). High-capacity dense space division multiplexing transmission. Opt. Fiber Technol, 35, 108-117. https://doi.org/10.1016/j.yofte.2016.09.015

Nishio, T., \& Numai, T. (2013). Dependence of total bandwidth and four-wave-mixing noises in FDM optical fiber transmission systems on the number of base units. Opt. Commun. 286, 313-317. https://doi.org/10.1016/j.optcom.2012.07.067

Raddatz, L., White, I.H., Cunningham, D.G., \& Nowell, M.C. (1998). An experimental and theoretical study of the offset launch technique for the enhancement of the bandwidth of multimode fiber links. J. Light. Technol, 16, 324-331. https://doi.org/10.1109/50.661357

Telatar, E. (1999). Capacity of Multi-antenna Gaussian Channels: Capacity of Multi-antenna Gaussian Channels. Eur. Trans. Telecommun, 10, 585-595. https://doi.org/10.1002/ett.4460100604

Tsekrekos, C.P. (2008). Mode group diversity multiplexing in multimode fiber transmission systems. Technische Universiteit Eindhoven.

Winzer, P.J., Chen, H., Ryf, R., Guan, K., \& Randel, S. (2014). Mode-dependent loss, gain, and noise in MIMO-SDM systems, in: 2014 The European Conference on Optical Communication (ECOC). Presented at the 2014 European Conference on Optical Communication (ECOC), IEEE, Cannes, France, pp. 1-3. https://doi.org/10.1109/ECOC.2014.6963888

\section{Copyrights}

Copyright for this article is retained by the author(s), with first publication rights granted to the journal.

This is an open-access article distributed under the terms and conditions of the Creative Commons Attribution license (http://creativecommons.org/licenses/by/3.0/). 